\title{
HUMAN SPERMATIDS AND SPERMATOZOA LACKING ACROSOMES
}

\author{
A. F. HOLSTEIN, C. SGHIRREN AND G. G. SCHIRREN \\ Department of Functional Anatomy and Department of Andrology, \\ University of Hamburg, 2 Hamburg 20, Martinistrasse 52, Germany
}

(Received 13th November 1972)

\begin{abstract}
Summary. Exclusively round-headed spermatozoa were detected in the ejaculates of four infertile adult males. Electron microscopy of ejaculate and biopsy material demonstrated that all such spermatozoa were devoid of acrosomes. Abnormal acrosomal development, independent of spermatid nuclei, occurred during the differentiation phase of spermatogenesis. The acrosome was incorporated into the Sertoli cell after release of the spermatozoon from the germinal epithelium.
\end{abstract}

\section{INTRODUCTION}

Three developmental processes are recognized in germinal cells during the last or 'differentiation' phase (Holstein \& Wartenberg, 1970) of spermatogenesis: (1) acrosome formation; (2) nuclear condensation; and (3) tail formation. From investigations carried out on bull spermatozoa (Schulte \& Ehrlich, 1954; Saacke, Amann \& Marshall, 1968) and boar spermatozoa (Bane \& Nicander, 1966), it is known that defects of the acrosome may cause sub- or infertility.

Literature on acrosomal malformations in man is scanty (Matano, 1971) and a complete analysis of the process of abnormal acrosomal development is lacking. As a result of investigating an infertile male patient whose ejaculates were found to contain spermatozoa, all of which showed the same type of acrosomal malformation (Schirren, Holstein \& Schirren, 1971) and subsequently detecting the same type of acrosomal malformation in three additional patients, it became possible to describe a process of abnormal acrosomal formation.

\section{MATERIALS AND METHODS}

Ejaculates and testicular biopsy material were obtained from four men aged 31 , 33,35 and 37 and were examined by light and electron microscopy. Within 20 min of collection, a few drops of the ejaculate were fixed for 30 min in PAFmixture of 900 mosmol (Stefanini, De Martino \& Zamboni, 1967) and postfixed in $1 \%$ OsO4 dissolved in $0.05 \mathrm{~mol}$ phosphate buffer containing $0.68 \mathrm{~g}$ sucrose $/ 100 \mathrm{ml}$.

Biopsy specimens from the right and left testes of patients were initially fixed 
in $6 \%$ glutaraldehyde in $0.1 \mathrm{~m}$-phosphate buffer (900 mosmol) and then postfixed in phosphate-buffered OsO4. Dehydration was performed in alcohol and embedding in Epon 812. Ultrathin sections, prepared on an ultramicrotome OmU2 (Reichert) using diamond knives, were 'contrasted' with lead citrate (Reynolds, 1963) and analysed in a Philips EM 300.

\section{RESULTS}

In early spermatids, the Golgi apparatus at first forms several clear vesicles which fuse to yield the so-called acrosomal vesicle. Normally, the vesicle becomes attached to the spermatid's nucleus during regular acrosomal formation (Horstmann, 1961), but in the specimens from the infertile patients, the acrosomal vesicle did not become connected to the nucleus but remained independent in most cells. Occasionally a partial contact between the acrosomal vesicle and the nuclear envelope was established. The Golgi complex secreted a fine granular osmiophilic material into the acrosomal vesicle which was eccentrically deposited at the vesicle's membrane (Plate 1), at a site distant from the typical location. Normally the electron-dense material was deposited at the site of contact of the nucleus and the vesicle.

Even in later spermatids, the acrosomal vesicles developed independently of the nucleus. The amount of osmiophilic material in the acrosomal vesicle increased concomitantly with the diminution of the Golgi complex. The osmiophilic material became more electron-dense and developed peculiar but characteristic features which signified a malformation of the acrosome.

The following types of acrosomes were distinguished: (1) electron-dense material bounded by a limiting membrane and containing many vesicles of very different size, some of which showed inclusions of a faintly electron-dense granular substance; (2) electron-dense material condensed to lamellar shell-like bodies that impinged on dilated and flattened cisternae of the endoplasmic reticulum; (3) beside these types of malformed acrosomes, near-regular forms of acrosomes were also seen to develop. As in normal acrosomal formation, the osmiophilic electron-dense material adopted a bell-like shape and surrounded an empty vesicle of the endoplasmic reticulum as shown in Plate 2. In the elongated cytoplasm of the spermatid, the acrosome occupied a remote position, distant from the nucleus. This was not an isolated observation but was a feature of material from different patients.

The development of the nucleus and the tail followed regular patterns in most instances. In late spermatids, the nucleus showed the typical condensation of its caryoplasm. The nuclear envelope of spermatids lacking acrosomes showed a tendency to form a membranous body.

The mature spermatid was released from the germinal epithelium into the lumen of the seminiferous tubule when the condensation of the nucleus and formation of tail structures were completed. The acrosome was left behind and taken up into and digested from the cytoplasm of Sertoli cells (Plate 3).

Thus, regularly condensed nuclei of spermatozoa lacking acrosomes appeared in the ejaculate, sometimes covered with layers of cytoplasmic membranes (Plate 4). 
PLATE 1

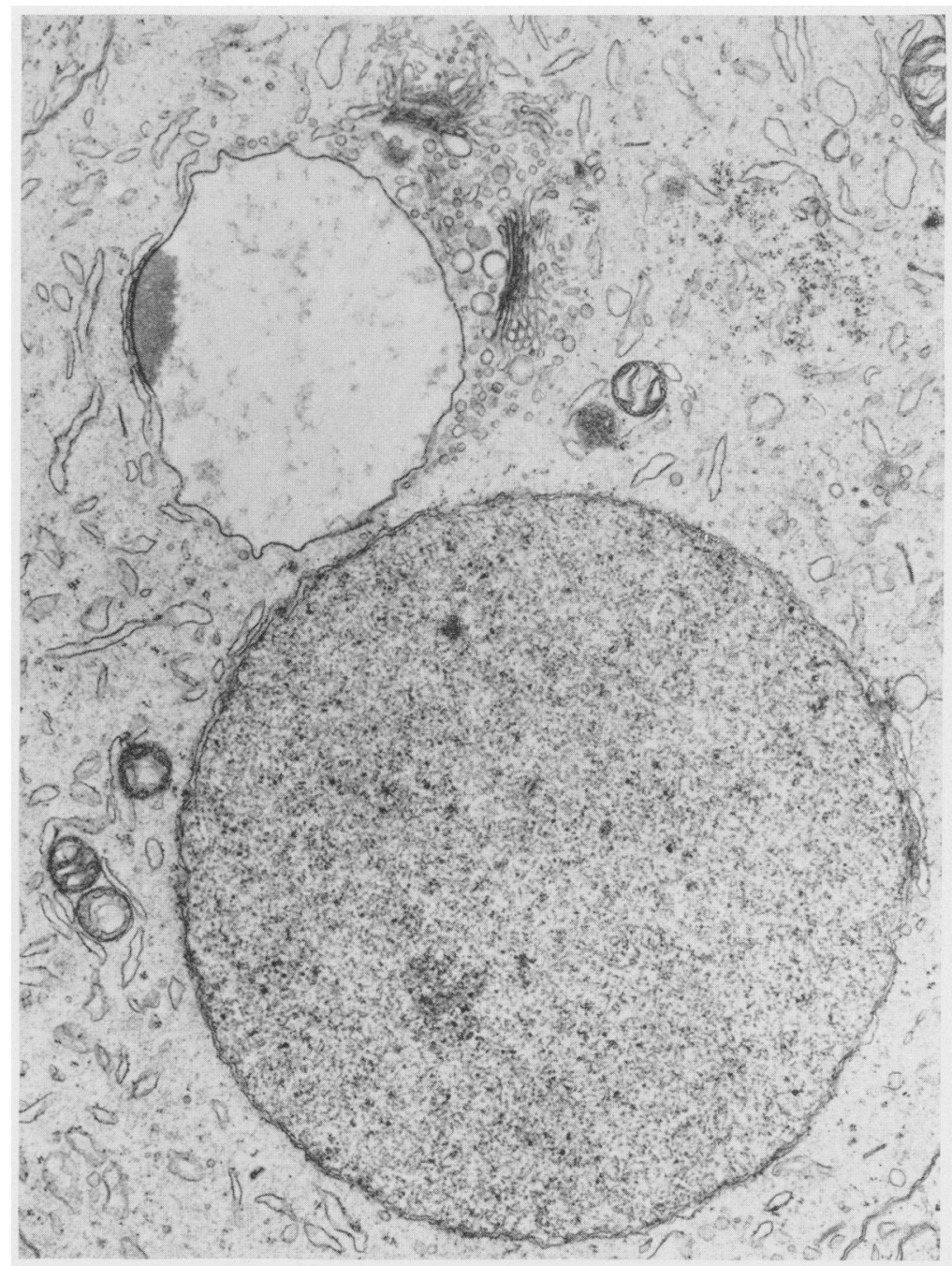

Fig. 1. An early spermatid from an infertile male showing the acrosomal vesicle developing independently of the nucleus. The osmiophilic acrosomal material is deposited at a site distant from the nuclcus of the spermatid. $\times 15,000$. 


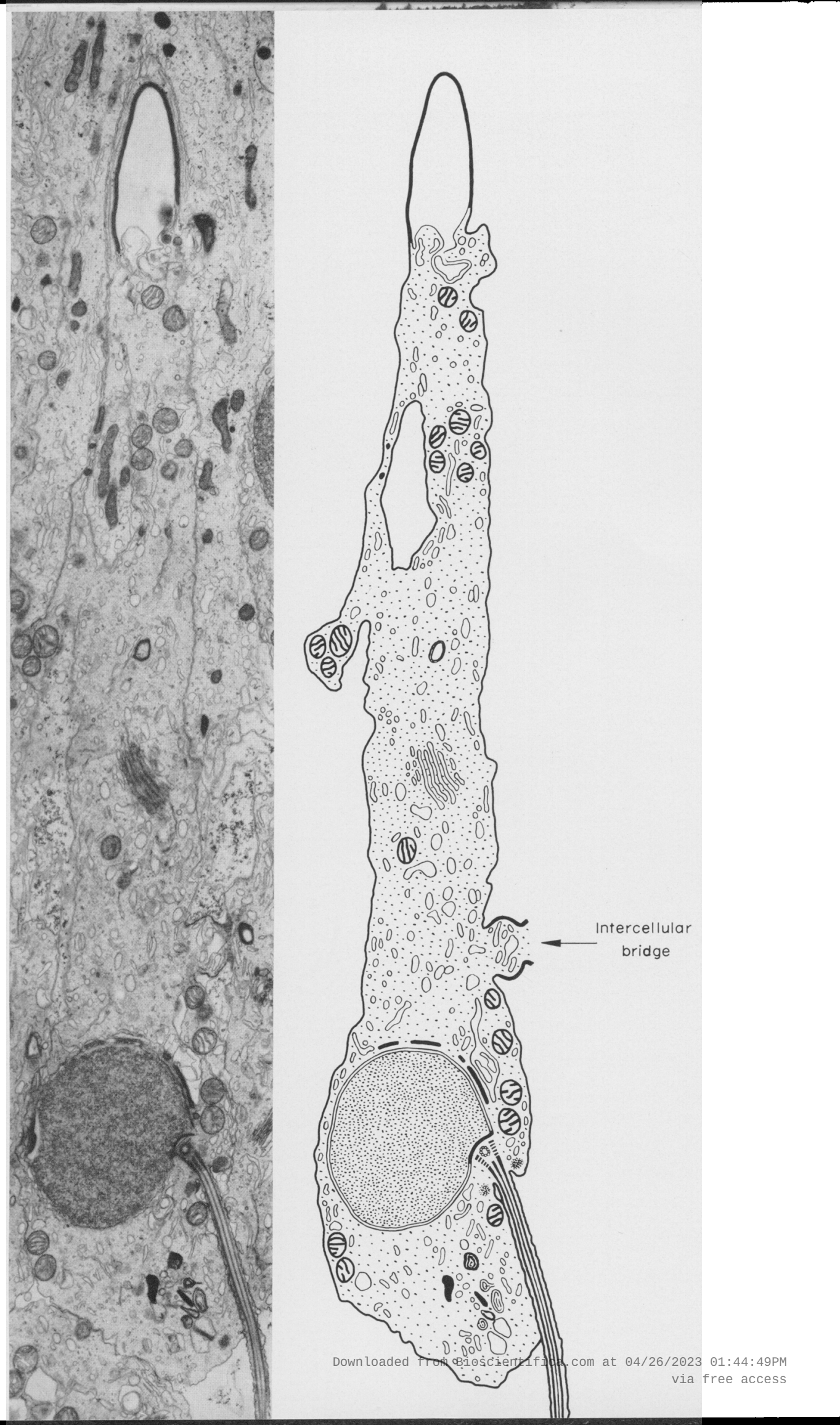


PLATE 3

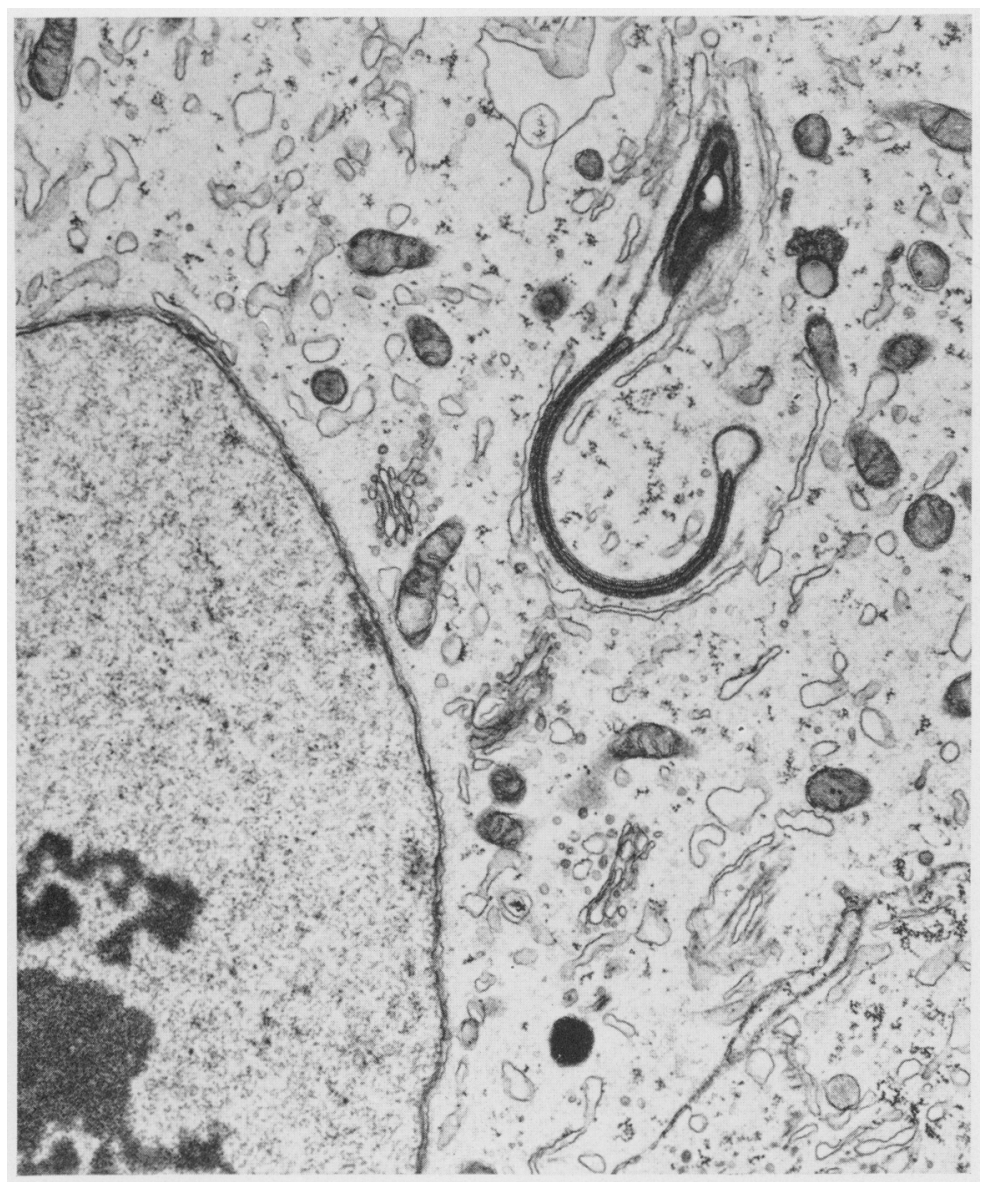

Fig. 3. An acrosome located in the cytoplasm of a Sertoli cell. $\times 14,000$.

PLATE 2 (on facing page)

Fig. 2. A spermatid from an infertile male showing an acrosome of near-normal size and typical form very distant from the nucleus. The acrosome embraces a large empty vacuole. Spherically shaped mitochondria and smooth endoplasmic reticulum are distributed throughout the elongated cell body. The nucleus of the spermatid is rounded and the tail structures appear normal. The spermatid is surrounded by Sertoli cells, recognizable by their elongated, dense mitochondria. On the right side of the micrograph, an intercellular bridge is seen to connect two spermatids. The graphical reconstruction presents a survey of the spermatids. $\times 11,400$. 


\section{PIA'T'E 4}

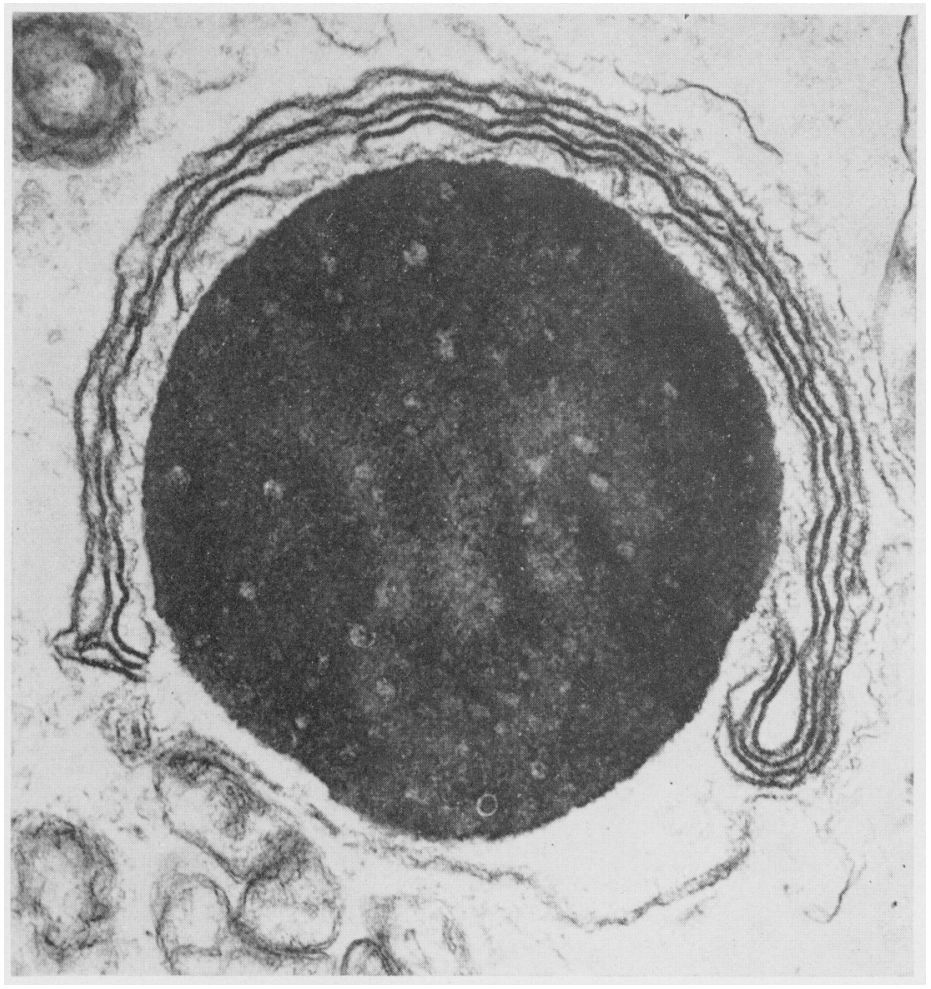

FIg. 4. Section of a spherically shaped head of a spermatozoon devoid of an acrosome (ejaculate spccimen). Several layers of membrane derived from the nuclear envelope are visible surrounding the sperm head. $\times 27,000$. 


\section{DISCUSSION}

A malformation of the acrosome has been detected in biopsy material from four infertile males that results in the production of spermatozoa lacking acrosomes. Analysis of the process of this malformation revealed that the acrosome formation was disturbed but the condensation of the nucleus followed a regular pattern and the formation of the tail was regular in most spermatids.

We suggest that this malformation originates in a defective 'anlage' of the Golgi apparatus and acrosomal vesicle. The acrosomal vesicle, differentiated from the Golgi complex of the spermatid, fails to establish contact with the spermatid's nucleus. The acrosomal vesicle then either transforms into a bizarre acrosomal body or becomes a bell-shaped acrosome, located somewhere in the cytoplasm of the spermatid and is left behind and incorporated into Sertoli cells after release of the spermatid from the germinal epithelium. Without an acrosome attached to it, the nucleus of the spermatid remains spherical.

No pathological alterations have been found in the nuclei of spermatids. The process of nuclear condensation seems to proceed independently of the malformation of the acrosome. More investigations are necessary to unravel interdependences of the individual developmental processes during the differentiation phase of spermatogenesis.

Round-headed spermatozoa are regularly seen in healthy males, but constitute a small percentage of the total amount of spermatozoa in the ejaculate (Hotchkiss, 1944). Due to the infrequency of malformed spermatozoa in healthy adults, it has not been possible to establish whether they conform to the type of acrosomal disturbance characterized in this publication.

Where the ejaculates of a patient contain exclusively round-headed spermatozoa, it is safe to state that the type of acrosomal malformation described here is involved.

\section{ACKNOWLEDGMENT}

We are indebted to Dr Baumgarten, Hamburg, for translation of the manuscript.

\section{REFERENCES}

BANE, A. \& NicANDER, L. (1966) Electron and light microscopical studies of spermateliosis in a boar with acrosome abnormalities. F. Reprod. Fert. 11, 133.

Holstein, A. F. \& WARTENBERG, H. (1970) On the cytomorphology of human spermatogenesis. In: Fortschritte der Andrologie, Vol. 1: Morphological Aspects of Andrology. Eds. A. F. Holstein and E. Horstmann. Grosse-Verlag, Berlin.

HorstmanN, E. (1961) Elektronenmikroskopische Untersuchungen zur Spermiohistogenese beim Menschen. Z. Zellforsch. mikrosk. Anat. 54, 68.

Hotchriss, R. S. (1944) Fertility in men. Lippincott, Philadelphia.

Matano, Y. (1971) Ultrastructural study on human binucleate spermatids. F. Ultrastruct. Res. 34, 123.

REYNoLDs, E. S. (1963) The use of lead citrate at high pH as an electron opaque stain in electron microscopy. F. Cell Biol. 17, 208.

SaAcke, R. G., Amann, R. P. \& Marshall, C. E. (1968) Acrosomal cap abnormalities of sperm from subfertile bulls. F. Anim. Sci. 27, 1391 .

Schirren, C. G., Holstein, A. F. \& Schirren, C. (1971) Über die Morphogenese rundköpfiger Spermatozoen des Menschen. Andrologie, 3, 117.

Schulte, F. \& EнrLich, J. (1954) Impotentia generandi eines Jungbullen infolge Akrosomdefektes der Samenzellen. Dt. tierärztl. Wschr. Beilage Fortpfl, Zuchthyg. Haustierbesamung, 4, 90.

Stefanini, M., de Martino, C. \& Zamboni, L. (1967) Fixation of ejaculated spermatozoa for electron microscopy. Nature, Lond. 216, 173. 